\title{
Efficacy of intravenous infusions of UC-derived MSCs for the treatment of COVID-19: A structured summary of a phase II double blinded, randomized controlled clinical trial
}

\section{Muhammad Ali}

Allama Iqbal Medical Research Centre, Jinnah Burn and Reconstructive Surgery Centre, University of Health Sciences, Lahore 54550 Pakistan

\section{Azra Mehmood}

National Centre of Excellence in Molecular Biology, University of the Punjab, Lahore 53700 Pakistan Moazzam Nazeer Tarar

Allama Iqbal Medical Research Centre, Jinnah Burn and Reconstructive Surgery Centre, University of Health Sciences, Lahore 54550 Pakistan

\section{Zafar Nawaz}

Department of Molecular Biology, University of Miami, Miller School of Medicine, Florida, USA

\section{S. Amer Riazuddin}

The Wilmer Eye Institute, Johns Hopkins University School of Medicine, Baltimore MD 21287 USA

\section{Aisha Khan}

Interdsciplenary Stem Cell Institute, University of Miami, Miller School of Medicine, Florida, USA

\section{Sheikh Riazuddin ( $\nabla$ riazuddin@aimrc.org )}

Allama Iqbal Medical Research Centre, Jinnah Burn and Reconstructive Surgery Centre, University of Health Sciences, Lahore 54550 Pakistan

\section{Method Article}

Keywords: COVID-19, umbilical cord, mesenchymal stem cells, intravenous infusion

Posted Date: October 28th, 2020

DOI: https://doi.org/10.21203/rs.3.rs-92995/v2

License: (a) (i) This work is licensed under a Creative Commons Attribution 4.0 International License. Read Full License 


\section{Abstract}

In this clinical research project, we will conduct a highly rigorous clinical trial where we randomize the patients between umbilical cord (UC)-derived mesenchymal stem cell (MSC) and standard of care (SOC). This study will ask the question whether the allogenic MSCs are effective in reducing death and/or progression of COVID-19 disease when administered to patients with moderate to severe symptoms. MSCs are unique group of cells with minimal immune reactivity and produce multiple beneficial effects, which include reduction of severe inflammatory reaction. There is convincing evidence from human studies that intravenous (IV) delivery of MSCs can directly impact the hyper-inflammatory responses of COVID-19 induced injury of the heart and lungs. Our study will evaluate the safety and efficacy of allogenic UC-derived MSCs administered intravenously to COVID-19 patients with moderate to severe symptom in a randomized, controlled clinical trial. In addition, we will determine whether : (i) UC-derived MSCs are effective in reducing 30-day all-cause mortality (primary endpoint) and (ii) UC-derived MSCs are effective in preventing progression to mechanical ventilation, and/or reducing an inflammatory response, and/or improving overall patient condition (secondary endpoints).

\section{Introduction}

Coronavirus disease (COVID-19) is an infectious disease caused by the newly discovered virus from SARS-CoV-2 family of viruses can cause illnesses such as common cold, severe acute respiratory syndrome (SARS), and Middle East Respiratory Syndrome (MERS). Coronavirus is an enveloped singlestranded RNA virus that causes distress in respiratory, enteric, hepatic and neurological systems with varying severity among human (1-2). The main symptoms of COVID-19 include fever, fatigue, and cough that can progress rapidly to severe and critical conditions resulting in pulmonary edema leading to acute lung injury (ALI) and acute respiratory distress syndromes (ARDS) (3-7).

In the last eight months or so, it has spread to 188 countries and as of October 14, 2020, it has infected more than 38 million people with 1,083,234 deaths worldwide (8). Importantly, there are currently no approved drugs or vaccines for the treatment of COVID-19 patients. The clinical spectrum of COVID-19 stems from over-activated immune system of the infected subjects, to kill the virus, which can induce/stimulate/ give rise to the production of a large number of inflammatory factors, resulting in a severe "cytokine storm". The cytokine storm may induce organ damage followed by edema, dysfunction of air exchange, acute respiratory distress, acute cardiac injury, and secondary infection, which may lead to death.

Stem cell therapy has emerged as a revolutionary treatment for diseases that were considered untreatable only a few years ago. Umbilical cord (UC)-derived mesenchymal stem cells (MSCs) have been shown to repair damaged liver, kidney, heart, pancreas, skin, cartilage, and cornea in animal models and in several human trials (9-15). In addition to cellular replacement through regeneration, UC-derived MSCs mediate through paracrine signaling pathways resulting in immune modulation. During the past eight months, several reports have been published (16-19) that suggest, MSCs, may prevent the cytokine storm and thus 
reduce the COVID-19 related morbidity. These reports, taken together (16-19) with our previous successes (20-21) with stem cell therapy in animal models has persuaded us to explore the MSC-based therapy for the treatment of COVID-19 patients. Here, we propose to evaluate the therapeutic efficacy of intravenous infusions of UC-derived MSCs in the treatment of COVID-19. The primary objective will be to demonstrate the safety of UC-derived MSCs administered intravenously in COVID-19 patients with moderate to severe COVID-19. Specific secondary objectives include improvements in comparison to the standard of care: general mortality, systemic inflammation, COVID-19 viral load, sequential organ failure assessment (SOFA), and chest imaging changes. The proposed investigation will have a duration of 30 days of active participant follow-up.

\section{Rationale}

COVID-19-induced severe respiratory illness is associated with acute respiratory distress syndrome (ARDS); a recent retrospective cohort study of 201 patients in a Wuhan hospital found that $41.8 \%$ of severe COVID-19 case patients developed ARDS, and a shocking $52.4 \%$ of those patients died (22). No specific anti-viral treatment currently exists. The mainstay of clinical management is largely symptomatic treatment, with organ support in intensive care for seriously ill patients. Cellular therapy, using MSCs has been shown to reduce inflammation and affect tissue regeneration and is being evaluated in patients with ARDS (23). Recognizing the inherent characteristics of UC-derived MSC, it is hypothesized that infusion of these cells may provide therapeutic relief in COVID-19 patients with ARDS and may be used as a novel treatment of the infections.

\section{Design And Study Plan}

The phase II study aims to recruit 20 subjects to assess the safety and efficacy of UCderived MSCs for treatment of COVID-19 versus standard of care (SOC) during 30 day follow up. It is two arms randomized study. Subjects will be divided in the following 2 groups:

Group 1: Fifteen subjects will be treated with three intravenous infusions of $5 \times 10^{5}$ (per $\mathrm{kg}$ body weight) UC-derived MSCs delivered via peripheral intravenous infusion on days 1, 3, and 5 besides the SOC.

Group 2: Five subjects will be treated under SOC. Two subjects in group 1 will not be treated 24 hours apart. Patients will be randomized in a 3:1 ratio (UC-derived MSCs : SOC). We propose to use this intervention at the onset of moderate to severe COVID-19. Figure 1 outlines the course of the disease.

\section{Outcome measures}




\section{Primary outcome measures:}

- Safety and efficacy assessment of infusion associated adverse events

- Chest radiograph or chest CT scan

\section{Secondary outcome measures:}

- COVID-19 quantitative real-time PCR

- SOFA Score. Each organ system is assigned a value for 0 (normal) to 4 (highest degree of dysfunction)

- Rate of all-cause mortality (measured at day 30 or at hospital discharge, whichever comes first)

- Clinical respiratory changes

- Chest imaging changes for 30 days

- Complete blood count (CBC) with differential

- Comprehensive metabolic panel

- $\mathrm{CD}^{+}$and $\mathrm{CD}^{+}$cell count

- Interleukin (IL)-10 levels

- Tumor necrosis factor (TNF)- $\alpha$ levels

- C-reactive protein levels

- Lactate dehydrogenase levels

- D-dimer levels

- Ferritin levels

- pro-type B natriuretic peptide (pro-BNP) levels

- Improvement of clinical symptoms including duration of fever and respiratory efficacy of treatment

\section{Isolation and characterization of human UC-derived MSCs}

Human umbilical cord tissue along with informed consent forms will be collected from hepatitis B, C, and COVID-19 virus-negative women with healthy pregnancies during the Cesarean Section surgery after completion of normal gestation period. The cord tissue will be transported in sterile phosphate-buffered saline (PBS) containing 200 units $/ \mathrm{ml}$ penicillin and $200 \mu \mathrm{g} / \mathrm{ml}$ streptomycin on ice. In the biosafety cabinet, the cord will be washed with 45 changes of sterile $1 \mathrm{x}$ PBS and placed in a Petri plate with $15 \mathrm{ml}$ PBS. Next, the umbilical cord tissue will be minced after removal of blood vessels. Minced pieces will be treated with 
collagenase type-I (201 U/ml collagenase type I) for $\sim 3.5$ hours. Following centrifugation of digested lysate diluted with PBS, the cells will be seeded in tissue culture flasks and will be placed in an incubator at $5 \% \mathrm{CO}_{2}, 95 \%$ humidity at $37 \square \mathrm{C}$. The cells will be fed with fresh media comprising of Dulbecco's modified Eagle's medium (DMEM)-high glucose supplemented with 20\% Hyclone fetal bovine serum (FBS), 1\% 10,000 U/mL penicillin, and $10,000 \mu \mathrm{g} / \mathrm{mL}$ streptomycin every third day. UC-derived MSCs at passage 3 (P3) will be characterized at the time of cryopreservation using the immunocytochemical analysis to determine the expression of positive surface markers i.e. CD73, CD90, C105, and negative for CD34 and CD45. In addition, quality control analyses will include sterility analysis for any signs of bacterial and fungal contamination. The culture-expanded cells will be cryopreserved at P3 using standard cryopreservation protocol until used in the experiment.

\section{UC-derived MSC production facility}

Cell production will be performed in a designated clean room qualified to maintain air quality of ISO-9001: 2015 standards. All tissue handling and final product filling will be completed within a certified Class II Biological Safety Cabinet. Furthermore, all members of staff are required to gown-in to the clean room space with sterile, single-use personal protective gear. Clean room, certified to meet ISO-9001: 2015 standards, will be utilized for processing activities. The Facility has an established system for sanitization and disinfection of clean-room, and the equipment used in manufacturing processes, in order to produce aseptic conditions.

The organization maintains a quality enforcement program to ensure that each product supplied conforms to product specifications. Product release will be monitored by trained staff who has appropriate training and experience in evaluating and determining product quality. It will be ensured that personnel engaged in technical and scientific activities have the necessary technical and scientific education, training, background and experience to ensure competent performance of their assigned functions.

\section{Infusion of UC-derived MSCs in COVID-19 patients}

The stem cell preparation will be administered intravenously in three single infusions of $5 \mathrm{x}$ $10^{5}$ cells per kilogram body weight each on days 1,3 , and 5 in addition to the SOC. For the 
intravenous infusion, stem cells will be resuspended in $100 \mathrm{ml}$ of normal saline $(0.9 \%$ sodium chloride). The cell infusion will be performed for approximately 50 minutes with a speed of about 35 drops per minute. The patient will be critically assessed by the clinician during infusion as well as six hours post-infusion for infusional and allergic reactions. The laboratory, clinical, and radiological outcomes will be recorded according to parameters mentioned in Table 1.

\section{Time Frame}

All patients will be examined at the following time points:

Day -1 (baseline/ one day before the UC-derived MSCs injection) and

Day 1 after infusion

Day 3 after infusion

Day 5 after infusion

Day 7 for follow up

Day 14 for follow up

Day 21 for follow up

Day 30 for follow up

\section{Statistical methods}

All statistical comparisons will be made primarily between the baseline and final values using the Student's paired t-test. Results will be obtained as means and standard deviations. The $\mathrm{p}$ value $<0.05$ will be considered statistically significant. A 95\% confidence interval for the difference in means will be used for double confirmation.

\section{Patient recruitment criteria}

The study will recruit twenty patients suffering from COVID-19 with moderately severe symptoms. To participate in the proposed study, the patients must meet the following inclusion and exclusion criteria:

\section{Inclusion criteria:}

For inclusion, the subjects must comply with the following criteria:

- Provide written informed consent. 
- Male or female subjects older than 18 years of age at the time of signing the informed consent form.

- Must have a clinical diagnosis of COVID-19 with at least one of the clinical symptoms i.e. cough, fever $\geq 38^{\circ} \mathrm{C}$ or fatigue, and a positive result by the reverse-transcription polymerase chain reaction (RT-PCR) testing or equivalent.

- Subjects with moderate to severe COVID-19 symptoms. Moderate disease category symptoms include mild category with abnormal chest imaging or any degree of hypoxia requiring supplemental oxygen while severe disease category symptoms include moderate symptoms with worsening hypoxia compatible with mild ARDS $\left(\mathrm{PaO}_{2} / \mathrm{FiO}_{2}\right.$ $</=300$ but $>200$ ).

- Appropriate venous access.

- Female patients will be agreed to use recommended birth control until 6 months posttreatment.

- Must agree to conform with all study constraints including completing all study visits.

- Entails in-patient admission.

\section{Exclusion:}

The following exclusion criteria will be used:

- Male or female younger than 18 years of age.

- Subjects with mild COVID-19 symptoms. Mild disease category symptoms include fever, cough, headache, myalgia, sore throat, nasal congestion, nausea, vomiting, diarrhea, fatigue, anosmia and/or dysgeusia.

- A female who is pregnant, nursing the infant, or of child-carrying potential while not practicing effective contraceptive methods. Females to be included in the present study must undergo a blood pregnancy test at screening and before infusion.

- Failure to perform any of the evaluations necessary for endpoint analysis.

- Have a clinical history of melanoma within 3 years, i.e. subjects with prior malignancy must be disease-free for 3 years.

- History of drug abuse (illegal drugs or prescription medications not being used properly for a pre-existing medical condition) or alcohol abuse or documented medical or legal problems arising from the use of alcohol or drugs within the past 2 years.

- If found serum positive for HIV, hepatitis B or C.

\section{Events/visits schedule}


Treatment evaluation will be performed through study design including a schedule of event/visit follow-up as described below. It is a two arms study to evaluate the safety and potential efficacy of UC-derived MSC infusions for the treatment of COVID-19 infection. Visit 1: Screening, written consent, duration of fever and respiratory efficacy, chest imaging, quantitative real-time PCR, ELISA, CBC with differential, comprehensive metabolic panel, SOFA score, $\mathrm{CD}^{+}$and $\mathrm{CD}^{+}$cell count, IL-10 levels, TNF- $\alpha$ levels, Creactive protein levels, D-dimer levels, lactate dehydrogenase levels, ferritin levels, and proBNP levels will be evaluated.

Visit 2: Intravenous infusion of stem cells, adverse events, if any, duration of fever and respiratory efficacy, chest imaging, quantitative real-time PCR, ELISA, CBC with differential, comprehensive metabolic panel, SOFA score, IL-10 levels, TNF- $\alpha$ levels, Creactive protein levels, D-dimer levels, lactate dehydrogenase levels, ferritin levels, ICU monitoring report and pro-BNP levels will be examined.

Visit 3: Intravenous infusion of stem cells, adverse events, if any, duration of fever and respiratory efficacy, chest imaging, quantitative real-time PCR, ELISA, CBC with differential, comprehensive metabolic panel, SOFA score, IL-10 levels, TNF- $\alpha$ levels, Creactive protein levels, D-dimer levels, lactate dehydrogenase levels, ferritin levels, ICU monitoring report and pro-BNP levels will be evaluated.

Visit 4: Intravenous infusion of stem cells, adverse events, if any, Duration of fever and respiratory efficacy, chest imaging, quantitative real-time PCR, ELISA, CBC with differential, comprehensive metabolic panel, SOFA score, cell count, IL-10 levels, TNF- $\alpha$ levels, C-reactive protein levels, D-dimer levels, lactate dehydrogenase levels, ferritin levels, ICU monitoring report and pro-BNP levels.

Visit 5, Visit 6, Visit 7, Visit 8: Adverse events, if any, duration of fever and respiratory efficacy, chest imaging, quantitative real-time PCR, ELISA, CBC with differential, comprehensive metabolic panel, SOFA score, CD4 ${ }^{+}$and CD8 ${ }^{+}$cell count, IL-10 levels, TNF$\alpha$ levels, C-reactive protein levels, D-dimer levels, lactate dehydrogenase levels, ferritin levels, and pro-BNP levels will be examined.

\section{Scheme of assessment:}


Table 1: The timeline and events plan for the conduct of the study.

\begin{tabular}{|c|c|c|c|c|c|c|c|c|c|}
\hline \multirow[b]{2}{*}{ Parameters } & \multicolumn{9}{|c|}{ Time from Infusion (Days) } \\
\hline & $\begin{array}{c}\text { Baseline/ } \\
\text { Day -1 } \\
\text { (Medical } \\
\text { History) }\end{array}$ & $\begin{array}{c}\text { Normal/ } \\
\text { Standard } \\
\text { Values }\end{array}$ & $\begin{array}{c}\text { Day of } \\
\text { first } \\
\text { infusion } \\
\text { /Day } \\
+1\end{array}$ & $\begin{array}{c}\text { Day of } \\
\text { second } \\
\text { infusion } \\
\text { /Day } \\
+3\end{array}$ & $\begin{array}{c}\text { Day of } \\
\text { Third } \\
\text { infusion } \\
\text { /Day } \\
+5\end{array}$ & Day+7 & Day+14 & Day+21 & Day+30 \\
\hline $\begin{array}{l}\text { Intravenous infusion } \\
\text { of stem cells }\end{array}$ & & & $\mathbf{x}$ & $\mathbf{x}$ & $\mathbf{x}$ & & & & \\
\hline $\begin{array}{l}\text { Adverse events, if } \\
\text { any, }\end{array}$ & & & $\mathbf{x}$ & $\mathbf{x}$ & $\mathbf{x}$ & $\mathbf{x}$ & $\mathbf{x}$ & $\mathbf{x}$ & $\mathbf{x}$ \\
\hline $\begin{array}{l}\text { Duration of fever and } \\
\text { respiratory efficacy }\end{array}$ & $\mathrm{x}$ & $\mathrm{x}$ & $\mathrm{x}$ & $\mathrm{x}$ & $\mathrm{x}$ & $\mathrm{x}$ & $\mathrm{x}$ & $\mathrm{x}$ & $\mathrm{x}$ \\
\hline Chest imaging & $\mathbf{x}$ & $\mathbf{x}$ & $\mathbf{x}$ & $\mathbf{x}$ & $\mathbf{x}$ & $\mathrm{x}$ & $\mathbf{x}$ & $\mathbf{x}$ & $\mathbf{x}$ \\
\hline $\begin{array}{l}\text { Quantitative real-time } \\
\text { PCR }\end{array}$ & $\mathbf{x}$ & $\mathbf{x}$ & $\mathbf{x}$ & $\mathbf{x}$ & $\mathbf{x}$ & $\mathrm{x}$ & $\mathbf{x}$ & $\mathbf{x}$ & $\mathbf{x}$ \\
\hline $\begin{array}{l}\text { ELISA } \\
\text { Results } \\
\text { Serum } \\
\text { Urine }\end{array}$ & $\mathbf{x}$ & $\mathbf{x}$ & $\mathbf{x}$ & $\mathbf{x}$ & $\mathbf{x}$ & $\mathbf{x}$ & $\mathbf{x}$ & $\mathbf{x}$ & $\mathbf{x}$ \\
\hline $\mathrm{CBC}$ with differential & $\mathrm{x}$ & $\mathrm{x}$ & $\mathrm{x}$ & $\mathrm{x}$ & $\mathrm{x}$ & $\mathrm{x}$ & $\mathrm{x}$ & $\mathrm{x}$ & $\mathrm{x}$ \\
\hline $\begin{array}{l}\text { Comprehensive } \\
\text { metabolic panel }\end{array}$ & $\mathbf{x}$ & $\mathbf{x}$ & $\mathbf{x}$ & $\mathbf{x}$ & $\mathbf{x}$ & $\mathbf{x}$ & $\mathbf{x}$ & $\mathbf{x}$ & $\mathbf{x}$ \\
\hline $\begin{array}{l}\text { Sequential organ } \\
\text { failure assessment } \\
\text { (SOFA) score }\end{array}$ & $\mathbf{x}$ & $\mathbf{x}$ & $\mathbf{x}$ & $\mathbf{x}$ & $\mathbf{x}$ & $\mathbf{x}$ & $\mathbf{x}$ & $\mathbf{x}$ & $\mathbf{x}$ \\
\hline $\begin{array}{l}\mathrm{CD} 4+\text { and } \mathrm{CD} 8+\text { cell } \\
\text { count }\end{array}$ & $\mathbf{x}$ & $\mathbf{x}$ & & & & $\mathrm{x}$ & $\mathbf{x}$ & $\mathbf{x}$ & $\mathbf{x}$ \\
\hline IL-10 levels (pg/ml) & $\mathrm{x}$ & $\mathrm{x}$ & $\mathrm{x}$ & $\mathrm{x}$ & $\mathrm{x}$ & $\mathrm{x}$ & $\mathrm{x}$ & $\mathrm{x}$ & $\mathrm{x}$ \\
\hline TNF- $\alpha$ levels ( $\mathrm{pg} / \mathrm{ml})$ & $\mathrm{x}$ & $\mathrm{x}$ & $\mathrm{x}$ & $\mathrm{x}$ & $\mathrm{x}$ & $\mathrm{x}$ & $\mathrm{x}$ & $\mathrm{x}$ & $\mathrm{x}$ \\
\hline $\begin{array}{l}\text { C-reactive protein } \\
\text { levels }(\mathrm{mg} / \mathrm{L})\end{array}$ & $\mathbf{x}$ & $\mathbf{x}$ & $\mathbf{x}$ & $\mathbf{x}$ & $\mathbf{x}$ & $\mathbf{x}$ & $\mathbf{x}$ & $\mathbf{x}$ & $\mathbf{x}$ \\
\hline D-dimer levels (ug/L) & $\mathbf{x}$ & $\mathrm{x}$ & $\mathrm{x}$ & $\mathrm{x}$ & $\mathbf{x}$ & $\mathrm{x}$ & $\mathbf{x}$ & $\mathrm{x}$ & $\mathrm{x}$ \\
\hline $\begin{array}{l}\text { Lactate } \\
\text { dehydrogenase levels } \\
\text { (U/L) }\end{array}$ & $\mathbf{x}$ & $\mathbf{x}$ & $\mathbf{x}$ & $\mathbf{x}$ & $\mathbf{x}$ & $\mathbf{x}$ & $\mathbf{x}$ & $\mathbf{x}$ & $\mathbf{x}$ \\
\hline Ferritin levels (ng/ml) & $\mathrm{x}$ & $\mathrm{x}$ & $\mathrm{x}$ & $\mathrm{x}$ & $\mathrm{x}$ & $\mathrm{x}$ & $\mathrm{x}$ & $\mathrm{x}$ & $\mathrm{x}$ \\
\hline $\begin{array}{l}\text { pro-BNP levels } \\
(\mathrm{pg} / \mathrm{ml})\end{array}$ & $\mathbf{x}$ & $\mathbf{x}$ & $\mathbf{x}$ & $\mathbf{x}$ & $\mathbf{x}$ & $\mathbf{x}$ & $\mathbf{x}$ & $\mathbf{x}$ & $\mathbf{x}$ \\
\hline $\begin{array}{l}\text { ICU Monitoring } \\
\text { Report }\end{array}$ & & & $\mathbf{x}$ & $\mathbf{x}$ & $\mathbf{x}$ & $\mathbf{x}$ & $\mathbf{x}$ & & \\
\hline Overall Improvement & & & $\mathbf{x}$ & $\mathbf{x}$ & $\mathbf{x}$ & $\mathbf{x}$ & $\mathbf{x}$ & $\mathbf{x}$ & $\mathbf{x}$ \\
\hline
\end{tabular}




\section{Potential side effects and hazards of the therapy:}

Allergic Reaction: it is possible that some patients experience an allergic reaction to UCderived MSCs. Possible allergic reactions include skin rash, sudden drop in blood pressure, loss of consciousness and/or associated seizures, or may have fatal effects.

Needle Insertion for IV Infusion: An experienced physician will perform this procedure. There may be discomfort due to needle insertion lasting a few minutes. Occasionally, a small accumulation of blood (hematoma) may form at the point of insertion of the needle. This may result in a small lump that will gradually disappear. Rarely, a small amount of bleeding or a local infection may occur around the needle insertion site. The amount of pain and discomfort will depend on pain tolerance of the subject. This usually lasts for 15-45 minutes during the actual procedure.

Blood Draw Risks: The blood drawing may accompany rare risks such as fainting, occurrence of temporary discomfort and/or bruise at the site of puncture. Rarely, infection or formation of a small clot or swelling in the vein and surrounding area may occur. Approximately 3 tablespoons of blood will be drawn at every study time point.

Steps taken to minimize the risks: The UC-derived MSCs undergo extensive screening and in-process controls to ensure purity and consistency during manufacturing.

Intravenous administration of study product, as well as blood draws will only be performed by qualified, licensed, medical experts. Although unanticipated, there is a hypothetical risk of thrombus formation associated with administration of any biologic product. Should the patient experience symptoms of thrombosis, based on the physician's judgment, the patient will be treated for thromboembolisms as per ICU protocol.

\section{References}

1. Zumla A, Chan JF, Azhar El, Hui DS and Yuen KY. Coronaviruses - drug discovery and therapeutic options. Nat Rev Drug Discov. 2016;15:327-47.

2. JF C, SK L and PC W. The emerging novel Middle East respiratory syndrome coronavirus: the "knows" and "unknows". J Formos Med Assoc. 2013;112:372-381. 
3. Ai T, Yang Z, Hou H, Zhan C, Chen C, Lv W, Tao Q, Sun Z and Xia L. Correlation of Chest CT and RTPCR Testing in Coronavirus Disease 2019 (COVID-19) in China: A Report of 1014 Cases. Radiology. 2020:200642.

4. Pan F, Ye T, Sun P, Gui S, Liang B, Li L, Zheng D, Wang J, Hesketh RL, Yang L and Zheng C. Time Course of Lung Changes On Chest CT During Recovery From 2019 Novel Coronavirus (COVID-19) Pneumonia. Radiology. 2020:200370.

5. Pan Y, Guan H, Zhou S, Wang Y, Li Q, Zhu T, Hu Q and Xia L. Initial CT findings and temporal changes in patients with the novel coronavirus pneumonia (2019-nCoV): a study of 63 patients in Wuhan, China. Eur Radiol. 2020.

6. Shi H, Han X, Jiang N, Cao Y, Alwalid O, Gu J, Fan Y and Zheng C. Radiological findings from 81 patients with COVID-19 pneumonia in Wuhan, China: a descriptive study. Lancet Infect Dis. 2020.

7. Cascella M, Rajnik M, Cuomo A, Dulebohn SC and Di Napoli R. Features, Evaluation and Treatment Coronavirus (COVID-19) StatPearls Treasure Island (FL); 2020.

8. WHO Coronavirus Disease (COVID-19) Dashboa https://covid19.who.int/

9. Chai NL, Zhang XB, Chen SW, Fan KX, Linghu EQ. Umbilical cord-derived mesenchymal stem cells alleviate liver fibrosis in rats. World J Gastroenterol. 2016;22(26):6036-48.

10. Guo Q, Wang J. Effect of combination of vitamin E and umbilical cord-derived mesenchymal stem cells on inflammation in mice with acute kidney injury. Immunopharmacol Immunotoxicol. 2018;40(2):168-172.

11. Liu CB, Huang H, Sun P, Ma SZ, Liu AH, Xue J, Fu JH, Liang YQ, Liu B, Wu DY, Lu SH, Zhang XZ. Human Umbilical Cord-Derived Mesenchymal Stromal Cells Improve Left Ventricular Function, Perfusion, and Remodeling in a Porcine Model of Chronic Myocardial Ischemia. Stem Cells Transl Med. 2016;5(8):1004-13.

12. Meng HB, Gong J, Zhou B, Hua J, Yao L, Song ZS. Therapeutic effect of human umbilical cordderived mesenchymal stem cells in rat severe acute pancreatitis. Int $\mathrm{J}$ Clin Exp Pathol. 2013;6(12):2703-12.

13. Meng Y, Shi C, Hu B, Gong J, Zhong X, Lin X, Zhang X, Liu J, Liu C, Xu H. External magnetic field promotes homing of magnetized stem cells following subcutaneous injection. BMC Cell Biol. 2017;18(1):24.

14. Richardson SM, Kalamegam G, Pushparaj PN, Matta C, Memic A, Khademhosseini A, Mobasheri R, Poletti FL, Hoyland JA, Mobasheri A. Mesenchymal stem cells in regenerative medicine: Focus on articular cartilage and intervertebral disc regeneration. Methods. 2016;99:69-80.

15. Yamashita K, Inagaki E, Hatou S, Higa K, Ogawa A, Miyashita H, Tsubota K, Shimmura S. Corneal Endothelial Regeneration Using Mesenchymal Stem Cells Derived from Human Umbilical Cord. Stem Cells Dev. 2018;27(16):1097-1108.

16. Leng Z, Zhu R, Hou W, Feng Y, Yang Y, Han Q, Shan G, Meng F, Du D, Wang S, Fan J, Wang W, Deng L, Shi H, Li H, Hu Z, Zhang F, Gao J, Liu H, Li X, Zhao Y, Yin K,He X, Gao Z, Wang Y, Yang B, Jin R, Stambler I, Lim LW, Su H, Moskalev A, Cano A, Chakrabarti S, Min KJ, Hughes GE, Caruso C, Jin 
K, Zhao Transplantation of ACE2(-) Mesenchymal Stem Cells Improves the Outcome of Patients with COVID-19 Pneumonia. Aging Dis. 2020;11(2):216-228.

17. Atluri S., Manchikanti L and Hirsch JA. Expanded Umbilical Cord Mesenchymal Stem Cells (UCMSCs) as a Therapeutic Strategy in Managing Critically III COVID-19 Patients: The Case for Compassionate Use. Pain Physician. 2020;23(2):E71-E83.

18. Liu J, Cao R, Xu M, Wang X, Zhang H, Hu H, Li Y, Hu Z, Zhong W and Wang M. Hydroxychloroquine, a less toxic derivative of chloroquine, is effective in inhibiting SARS-CoV-2 infection in vitro. Cell Discov. 2020;6:16.

19. Guo YR, Cao QD, Hong ZS, Tan YY, Chen SD, Jin HJ, Tan KS, Wang DY and Yan Y. The origin, transmission and clinical therapies on coronavirus disease 2019 (COVID-19) outbreak - an update on the status. Military Medical Research. 2020;7:11.

20. Riazuddin S et al., Book chapter: Stem cells for the repair of damaged skin and cartilage, in Book: Stem Cells - From Drug to Drug Discovery. Ed. by Haider, Khawaja Husnain; ISBN\# 978-3-11-0493764; March 2017.

21. Riazuddin S et al., Cell therapy for liver regeneration. In , (Eds.), Stem Cells - From Hype to Real Hope (pp. 130-145). Berlin, Boston: De Gruyter. https://doi.org/10.1515/9783110587043-007; Book DOI: https://doi.org/10.1515/9783110587043; Online ISBN: 9783110587043; @ 2018 Walter de Gruyter $\mathrm{GmbH}$, Berlin/Munich/Boston.

22. Wu C, Chen X, Cai Y, Xia J, Zhou X, Xu S, Huang H, Zhang L, Zhou X, Du C, Zhang Y, Song J, Wang S, Chao Y, Yang Z, Xu J, Zhou X, Chen D, Xiong W, Xu L, Zhou F, Jiang J, Bai C, Zheng J and Song Y. Risk Factors Associated With Acute Respiratory Distress Syndrome and Death in Patients With Coronavirus Disease 2019 Pneumonia in Wuhan, China. JAMA Intern Med. 2020.

23. Zheng G, Huang L, Tong H, Shu Q, Hu Y, Ge M, Deng K, Zhang L, Zou B, Cheng B and Xu J. Treatment of acute respiratory distress syndrome with allogeneic adipose-derived mesenchymal stem cells: a randomized, placebo-controlled pilot study. Respir Res. 2014;15:39.

\section{Declarations}

\section{Trial Status}

The trial is currently on hold and waiting for approval from the higher regulatory authorities of Pakistan.

\section{Trial registration}

https://clinicaltrials.gov/; ClinicalTrials.gov Identifier: NCT04437823; Registration date: June 18, 2020.

\section{Full protocol}

The full protocol is attached as an additional file, accessible from the Trials website Additional file 1. In the interest of expediting the dissemination of this material, the familiar formatting has been eliminated; this Letter serves as a summary of the key elements of the full protocol. 


\section{Keywords}

COVID-19, umbilical cord, mesenchymal stem cells, intravenous infusion.

\section{Declarations}

\section{Ethics approval and consent to participate}

This trial has received ethical approval from the Ethical Review Board (ERB) Allama Iqbal Medical Research Centre, Lahore, Pakistan.

\section{Consent for publication}

Not applicable

\section{Availability of data and materials}

The data will be available online after the completion of the study.

\section{Competing interests}

The authors declare that they have no competing interests.

\section{Funding}

Jinnah Burn and Reconstructive Surgery Centre, Lahore has been sponsoring the study.

\section{Authors' contributions}

Concept, coordination: SR, SAR Protocol design, ethics, and manuscript: SAR, SR, AM, MA, MNT, JDG, ZN, AK. The author(s) read and approved the final manuscript.

\section{Acknowledgments}

The authors thank all the medical staff, nurses and patients who have been fighting against COVID-19.

\section{Figures}




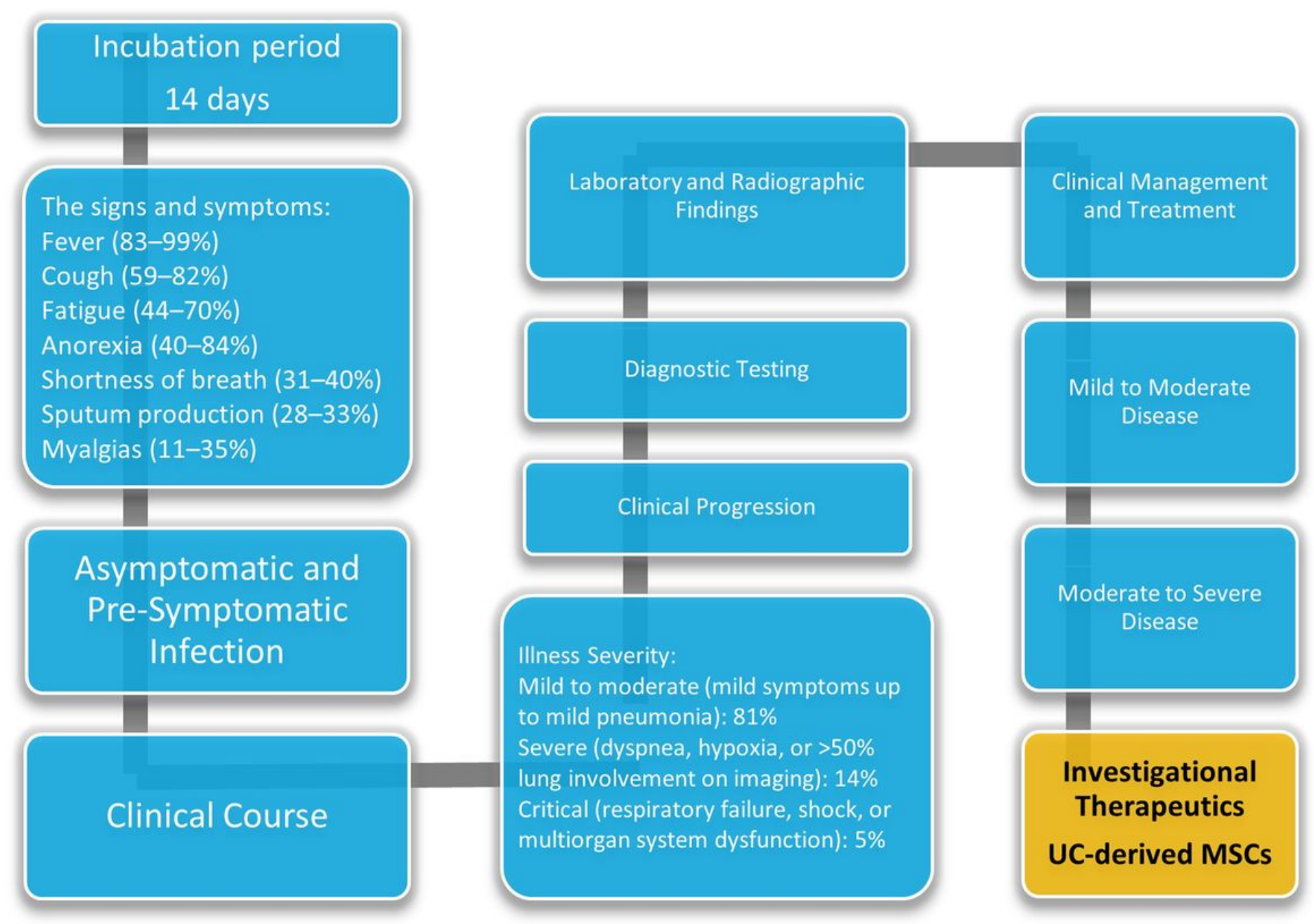

\section{Figure 1}

COVID-19 course of disease.

\section{Supplementary Files}

This is a list of supplementary files associated with this preprint. Click to download.

- AdditionalFile1.docx 